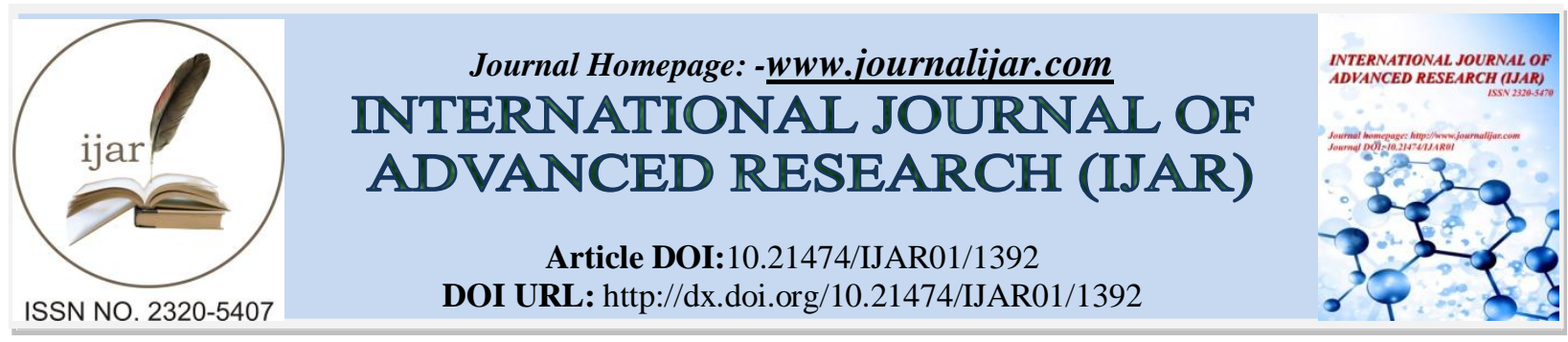

RESEARCH ARTICLE

\title{
MORPHOLOGY OF ANASCRECCA (COMMON TEAL) TONGUE
}

Neveen E. R. El Bakary ${ }^{1}$, Abu-Almaaty, A. H. ${ }^{2}$, Sarah H. Ahmed ${ }^{2}$ and Mohamed K. Hassan ${ }^{2}$.

1. Zoology Department, Faculty of Science, Damietta University.Egypt.

2. Zoology Department, Faculty of Science, Port Said University.Egypt.

\section{Manuscript Info}

Manuscript History

Received: 15 June 2016

Final Accepted: 19 July 2016

Published: August 2016

Key words:-

SEM-Tongue. Birds-Ducks.Histology

\section{Abstract}

The aim of this work is to examine the morphological features of the tongue of Anascrecca (common teal) of the Family Anatidaeusing light and scanning electron microscopy. The tongue is divided into apex, body and root. Here, our study shows that thesmall hair-like filiform lingual papillae are found on the lateral sides of the apex region of the tongue. Also, many processes are found on the horny tip of the tongue.The body region of the tongue of the common teal has several numbers of mechanical conical papillae on its lateral sides. In the body and root regions, there are large units of glands located in the lamina proparia. The anatomical characteristics of the tongue of Anascrecca (common teal)adapt to its life in the aquatic environment.

Copy Right, IJAR, 2016,. All rights reserved.

\section{Introduction:-}

Anseriformes is a large and complex group including approximately 150 species and showing very high worldwide variety (Gonzalez et al., 2009). The avian tongue has common variation in the anatomical characteristics in terms of structure, surface morphology and topographical distribution of lingual papillae as well as distinct specialized structures, epithelial layers, taste buds and lingual glands(Erdogan and Iwasaki, 2014).

The different studies on the avian tongueswere attributed the structural/anatomical variations of those tongues to the feeding habits as birds are adapted to live the different environmental conditions (Iwasaki, 2002). There are many examples for that such as white-tailed eagle (Jackowiak and Godynicki, 2005), cormorant (Jackowiaket al., 2006), peregrine falcon and common kestrel (Emuraet al., 2008), Japanese pygmy woodpecker (Emuraet al., 2009), blue-and-white flycatcher, hawfinch and Japanese white-eye (Emuraet al., 2010), common quail (Parchamiet al., 2010), rainbow lorikeet (Emuraet al., 2011), scarlet macaw (Emuraet al., 2012), white-breasted kingfisher (El Bakary, 2012)muscovy duck(Igwebuike and Anagor, 2013), whitethroated kingfisher and common buzzard (El-Beltagy, 2013), domestic goose (Anseranser f. domestica) and the domestic duck (Anasplatyrhynchos f. domestica)(Skiereszand and Jackowiak, 2014) and Northern Pintal(El Bakary, 2015).

Anascrecca (common teal) is an aquatic bird of family Anatidae.Itshows a preference for shallow permanent waters, Small freshwater lakes with abundant emergent vegetation are preferred. In spring and summer, the diet of the species consists predominantly of animal matter such as insects. During winter the species mainly takes the seeds of aquatic grasses, sedges and agricultural grain(Kear, 2005). 
Three mechanisms of feeding characterize neognathae birds: grazing, pecking and filtering food (Baussartet al., 2009). The present study aimed to investigate the anatomical structural adaptations of the tongue in the common tealhelped in its feeding mechanisms.

\section{Materials and methods:-}

All the investigated animals were mature and in good health.Anascreccawere obtained from the local markets in Port Said and Damietta. This study followed the guidelines for the care and use of laboratory animals and the animal welfare and Ethics Committee of the Faculty of Science, Damietta University according to the Egyptian's laws, approved it, in which satisfactory measures were taken to minimize pain or discomfort.

They were slaughtered and the head region of each bird was dissected, then gross photographs of the tongue were captured by a digital camera to show the morphological differences between the two investigated species.

\section{Light microscope study:-}

The extracted tongues of Anascreccawere cut into the three parts representing the three main regions of the tongue; apex, body and root regions. These parts were preserved in $10 \%$ formalin fixative, then dehydrated in an ascending series of alcohol, cleared in xylene and finally embedded in paraffin wax. Histological sections of different parts were prepared and stained with haemtoxyline and eosin in a histology laboratory in the Faculty of Science.

\section{Scanning electron microscope:-}

The tongues were fixed in $10 \%$ formalin, post-fixed with $1 \%$ osmium tetroxide for $1 \mathrm{~h}$ at $\mathrm{pH} 7.2$. Then, the specimens were dehydrated in a graded series of ethanol and critical point dried. Some of the samples were washed in distilled water after fixation. Then, they were fixed at $1 \%$ buffered osmium tetroxide for $1 \mathrm{~h}$. After washing three times, the specimens were dehydrated in a series of ethanol and critical point dried (Jackowiak andGodynicki, 2005). All specimens were mounted on aluminum stubs covered with carbon tabs, sputtered with gold and observed under JEOL scanning electron microscopy (JSM-5300) at an accelerating voltage of $15 \mathrm{kv}$ in electron microscopy unit at the Faculty of Science, Alexandria University.

\section{Results:-}

The total length of Anascrecca (common teal) tongue is $4.5 \mathrm{~cm}$ and its width is $0.9 \mathrm{~cm}$, whereby the apex measures $0.5 \mathrm{~cm}$, the body with the lingual prominence measures $3.5 \mathrm{~cm}$ and the root measures $0.5 \mathrm{~cm}$. The apex of the tongue of the Anascrecca (common teal)is roughly rounded with no lingual papillae within its smooth edge (Fig. 1). The median groove which divides the lingual mucosa into two equal parts continues till the root region (Fig. 1). The body region of the tongue has several numbers of mechanical conical papillae on its lateral sides. There is a triangular lingual prominence above the root region with 6 pairs of large and small conical papillae.Those are arranged in a single row at its end. The root region of the tongue is a relatively short region and communicated with the laryngeal prominence. The conical lingual papillae protruding from it and caudally directed. The glottis, a large oval opening, is apparent caudal to the root region (Fig. 1).

\section{Scanning electron microscopy (SEM):-}

Our results show that the lingual apex region of Anascrecca (common teal) is short and most of its dorsal surface was relatively smooth, without any lingual papillae but it has many processes which can be easily seen in the horny tip (Fig. 2-a,c). Using higher magnification, the superficial cells on the dorsal side of the apex region were seen (Fig. 2-b). There arefiliform lingual papillae arranged laterally on the sides of the apex region. They are small in size and hair like (Fig. 2-d,e) and the large conical papillae can be seen also in this region, which are in the form of cones with sharpened ends, Processes of these papillae are directed sideways and slightly caudally and are arranged, relative to the long axis of the tongue (Fig. 2-e).

In the body region, the giant conical papilla with blunt processes pointing to the back of the tongue, located near the lingual prominence, and among the conical papillae of the body, very densely arranged filiform papillae were conspicuous as hair like papillae (Fig. 3-a,b) These hair-like structures were organized in many rows along the giant processes in the lateral sides of the body region of the tongue.

In the root region of Anascrecca tongue, a transversal row of conical papillae was observed. Long conical papillae were located closer to each other. The bodies of these conical papillae were wider than other free papillae (Fig. 4). 


\section{Histology:-}

In Anascrecca (common teal), beneath the epithelium on both the dorsal and the ventral surfaces of the tongue apex there is dense irregular fibrous connective tissue, the lamina proparia which penetrates the epithelial layers in the form of connective tissue papillae (Fig. 5-a,b). The center of the tongue consists of hyoid cartilage with skeletal muscles (Fig. 5-a).

Mucous lingual glands can be found in the lamina proparia of the lingual submucosa in the body and root regions of the tongue. The lingual submucosa contains large numbers of simple branched tubular glands. These lingual glands appear as round, oval shaped. Each glandular unit is surrounded by a layer of highly vascularized connective tissue. (Fig. 5-c,d).

\section{Discussion:-}

All birds adapt to their habitats with respect to feeding mechanisms. Reflecting their different lifestyles, birds have different feeding habits, with corresponding differences in the structures of their bills and tongues (Emuraet al., 2008).

There are some important structures of the tongue of birds like a sieve in ducks, capillary tube in sunbirds, spear in woodpeckers, barbet in penguin, rasp in vulture and brush in Trichglossidae. These structures are considered as an essential tool for providing some clue to the major diet and way of feeding as in each species (Pasandet al..,2010; El-Bakary, 2011). The avian tongues are adapted for many important actions as collection, manipulation and swallowing of foods (Erdoğan and Iwasaki, 2014).

The Three mechanisms of feeding characterize neognathae birds: pecking and filtering food (Baussartet al., 2009). Several adaptations are observed in both the investigated species and helped in its feeding mechanism

The tongue of anascreccais elongated and oval, this is in accordance with Getty (1975), Hassan et al., (2010) and Iwasaki et al., (1997) and have special morphological characteristics that differ from ostrich (Strutiocamelus)(Jackowiak and Ludwig, 2008), Hoopoe (Upupaepops) (El-Bakary, 2011), Nutcracker (Nucifragacaryocatactes) (Jackowiaket al., 2010) and common kingfisher (Alcedoatthis) (Al-Zahaby and Elsheikh, 2014). The tip of the tongue of the investigated species with its lingual nail acts as spoon helps in collecting grains. These observations were in agreement with Jackowiaket al., (2011) in domestic goose.

The tongue in birds is divided into three parts as apex, lingual body, and root (Jackowiak and Godynicki, 2005). On the dorsal surface of the lingual body of Anascrecca, there is a median groove that divides the lingual mucosa into two equal parts continues till the root region found in the tongue of the investigated species which is also considered as a distinguishing mark for Middendorff's bean goose (Iwasaki et al., 1997), White tailed eagle (Jackowiak and Godynicki, 2005), Egyptian goose (Hassan et al., 2010) and nutcracker (Jackowiaket al., 2010).

Anascrecca tongue was characterized by filiform papillae found in the lateral and posterior part of the apex and in the body of the tongue.Conical papillary crest in the lingual body separated the lingual body from the lingual root and directed backward. Many pairs of mechanical conical papillae are located in the root region of the tongue, blade-like lamellae are significant tools for straining food. Food particles are strained out by lamellae of the bill and projections on the tongue (papillae) when water is expelled through the sides of the bill(Lagerquist and Ankney, 1989). Nudds and Bowlby (1984) demonstrated that in dabbling ducks, those species which have larger spaces between lamellae are allowed to consume larger prey (Lagerquist and Ankney, 1989). It has been indicated that in geese and ducks conical papillae also exist along the sides of the palate (Nickel et al., 1977; Sağsözet al., 2013).

Our study was in agreement with the study of Skieresz-Szewczyk andJackowiak, (2016) in the domestic duck in that the filtration apparatus ofAnascrecca (common teal) consists of small and large conical papillae and the filiform papillae which helped in filtering the food immersed in water.

Keratinization on the dorsal and ventral surface of Anascreccais a common character for feeding adaptation, which is similar to other avian tongues (Al-Zahaby and ElSheikh, 2014). There is a relationship between feeding habit and degree of keratinization. The herbivorous birds have a high degree of keratinization, while the aquatic forms have a lesser degree (Iwasaki, 1992,2002). 
The lingual glands have been observed in other avian species (Jackwiak and Godynicki, 2005). Mucous lingual glands can be found in the lamina proparia of the lingual sub-mucosa in the body and root regions of the tongue.

The lingual salivary glands have important functions in food lubrication and moisture, which help in rolling or sliding the food over the smooth tongue surface towards the esophagus (Jackowiak and Ludwig, 2008) Also, salivary glands play a role in the protection of the tongue surface from large material and desiccation (Tabaket al., 1982; Igwebuike and Anagor, 2013).

The tongue of Anascrecca (common teal) is adapted to terrestrial (pecking and grazing) and aquatic (filtering) habitat. The tongue has glands in the body and root of the tongue. During grazing and pecking the lingual glands helped in food moisture and pushing it to the esophagus. Mechanical papillae, lingual comb and lingual prominence helped in filtration which is the main feeding mechanism.

\section{List of figures:-}

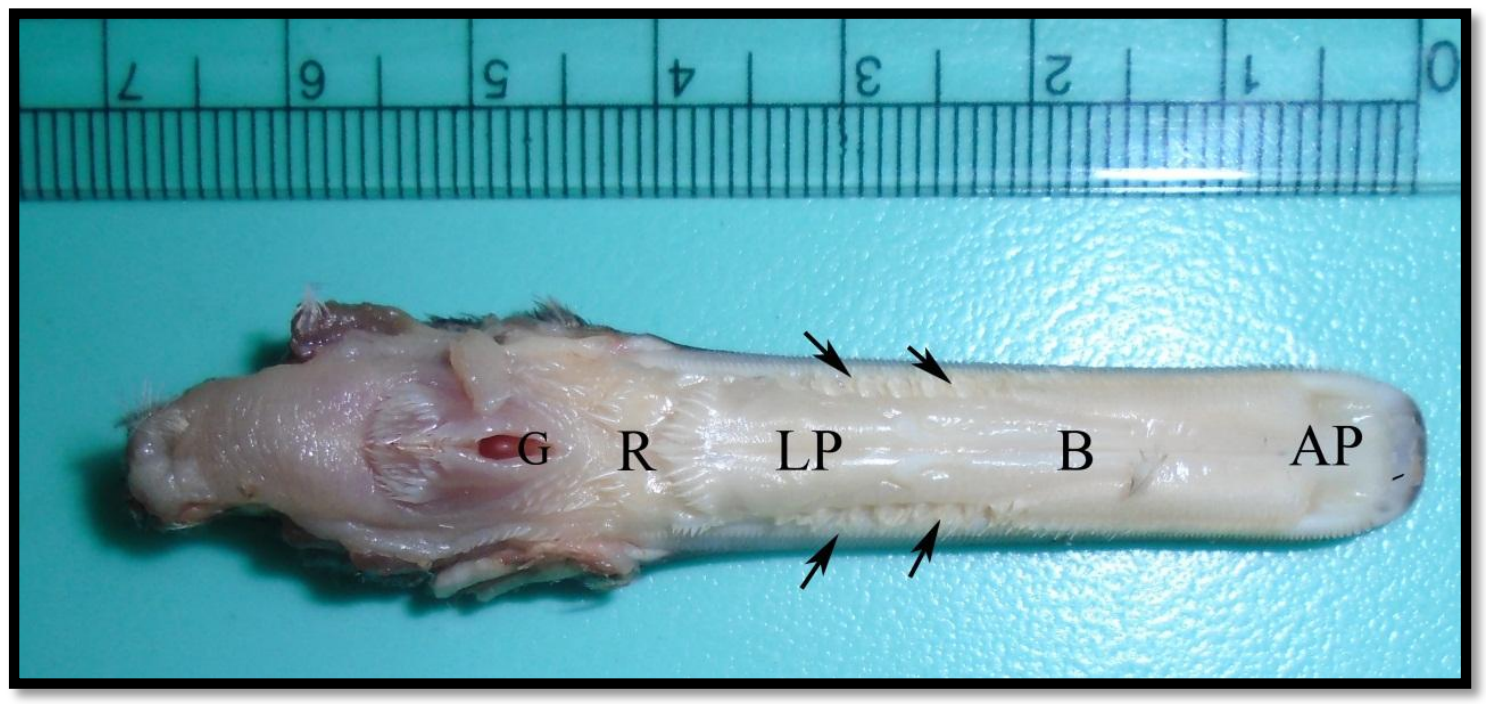

Fig. 1:- Dorsal view of the tongue in Anascrecca (common teal) showing its parts; apex (AP), body (B), root $(\mathrm{R})$, lingual prominence (LP) - Glottis fissure (G) and lingual papillae (black arrows). 


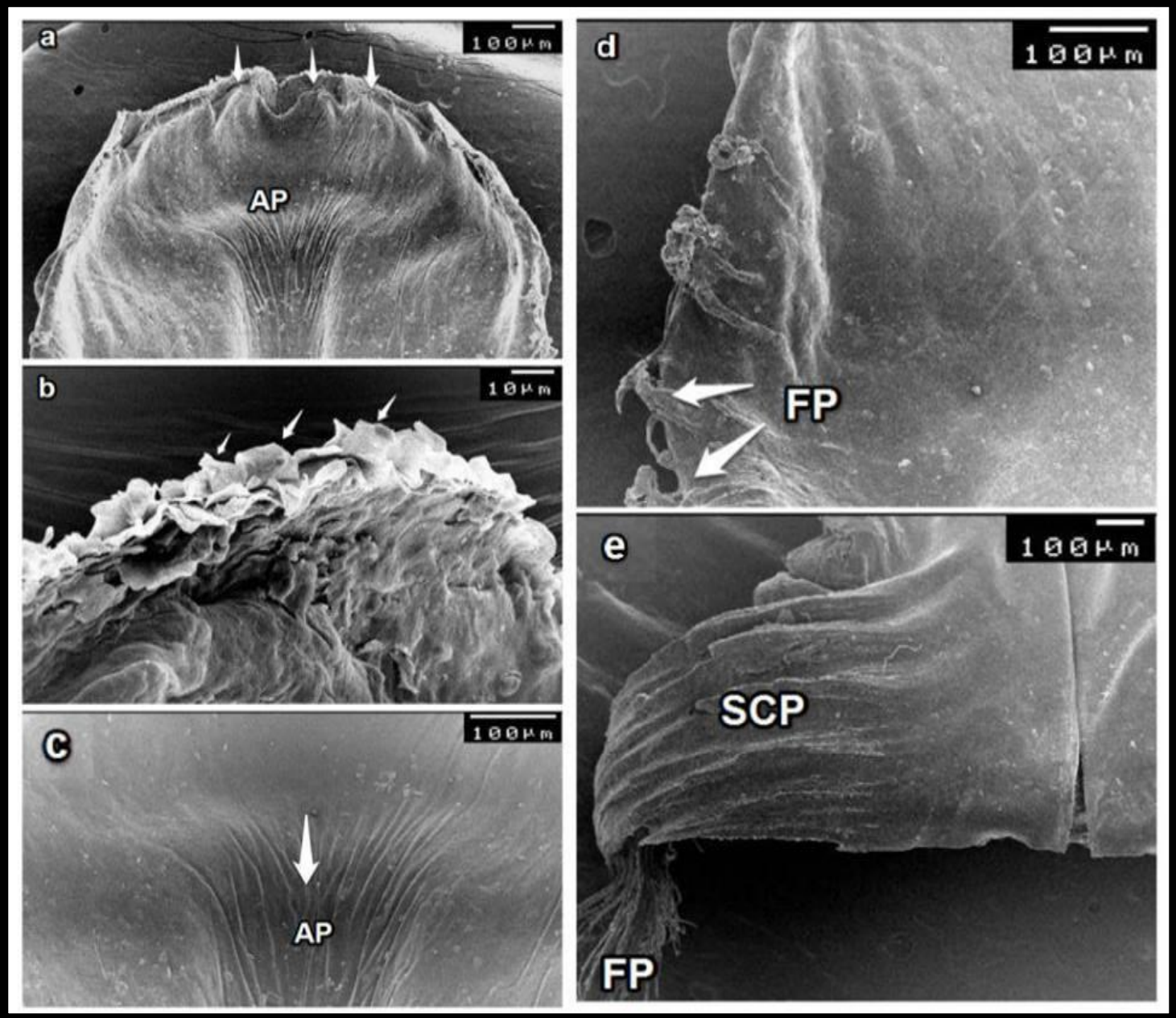

Fig. 2:- Scanning electron micrograph of the dorsal surface of the apex region of the tongue in Anascrecca (common teal), showing the horny tip with its processes (white arrows) of the apex (Ap). Scale bar: $100 \mu \mathrm{m}$ (a), the dorsal sub-epithelial surface of the lamina propria of the lingual mucosa of the apex (white arrows) Scale bar: $10 \mu \mathrm{m}$ (b), higher magnification of the middle apex region (Ap) with several folds in both sides of a lateral line (arrow). Scale bar: $100 \mu \mathrm{m}(\mathbf{c})$, the lateral side of the apex region of the tongue, filiform Lingual papillae (FP) Scale bar: $100 \mu \mathrm{m}$ (d), small conical papillae (SCP) and filiform papillae (FP) at the posterior part of the apex Scale bar: $100 \mu \mathrm{m}(\mathbf{e})$. 


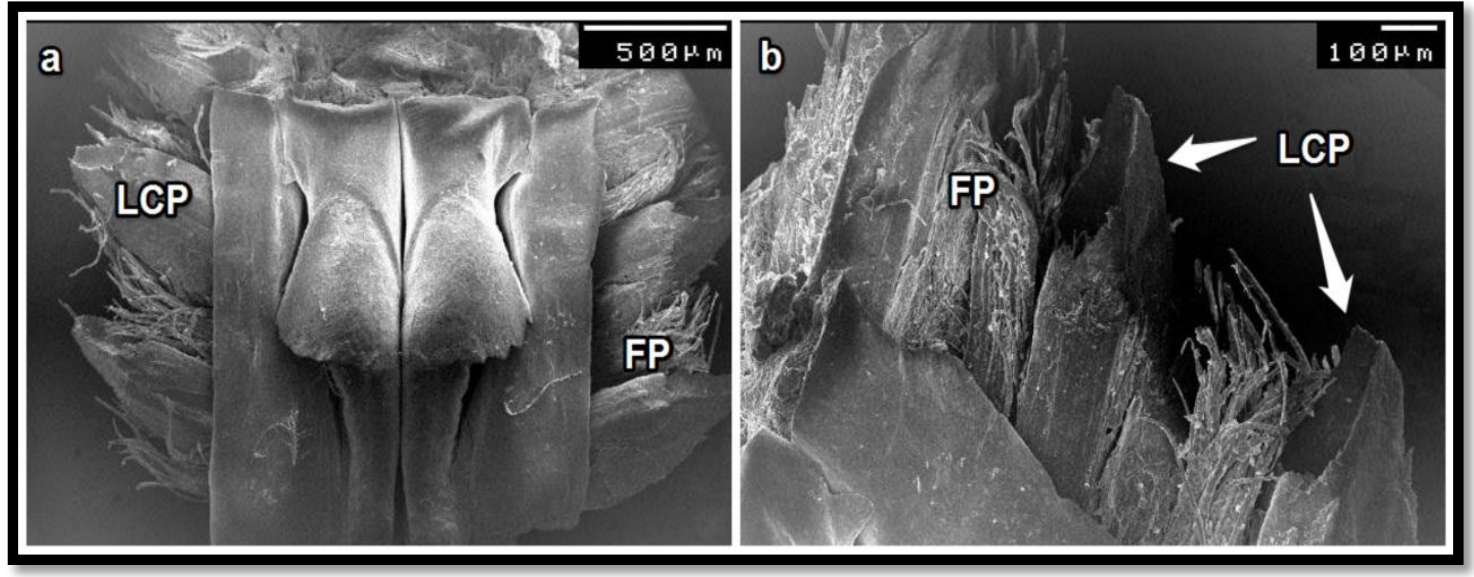

Fig. 3:- Scanning electron micrograph the of dorsal lingual surface of the body region in Anascrecca (common teal), showing both large conical papillae (LCP) and filiform papillae (FP) on the lateral sides of the tongue Scale bar: 500 $\mu \mathrm{m}$ (a), the large conical papillae (LCP) and the hair like filiform papillae (FP) on the lateral side of the tongue, Scale bar: $100 \mu \mathrm{m}(\mathbf{b})$.

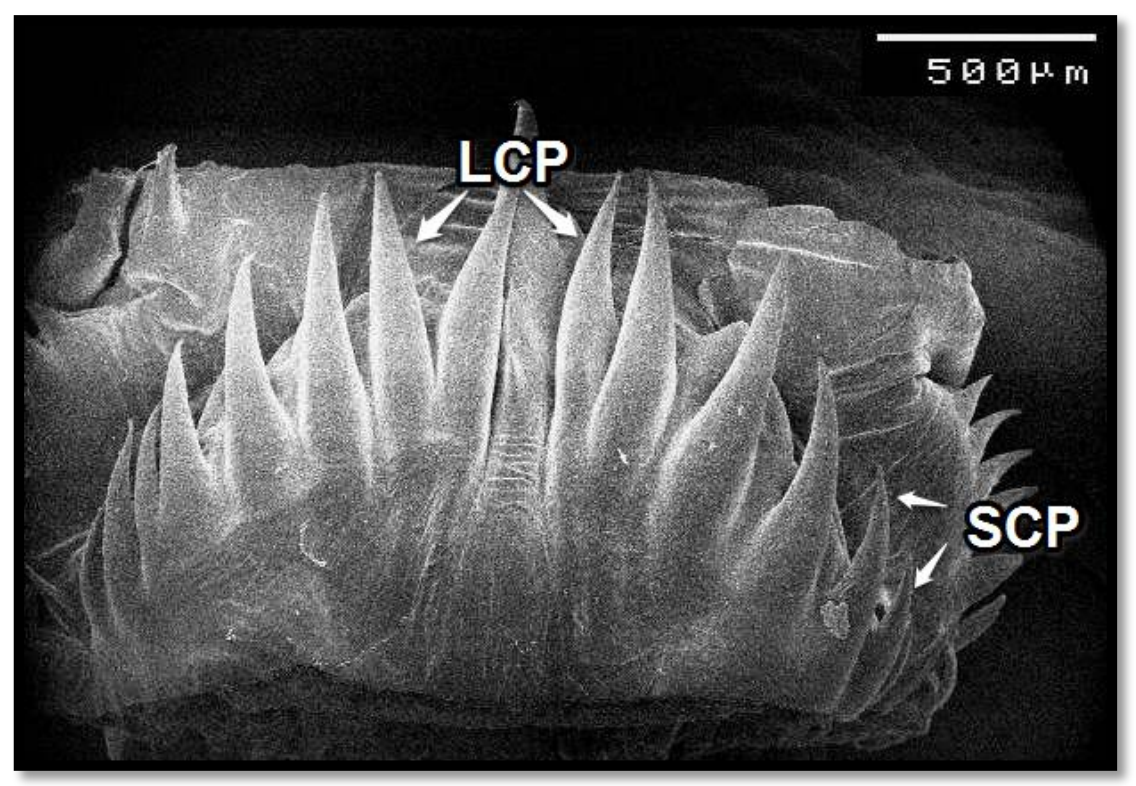

Fig. 4:- Scanning electron micrograph of dorsal lingual surface of root region in Anascrecca (common teal), showing the large conical papillae (LCP) and small conical papillae (SCP) Scale bar: $500 \mu \mathrm{m}$. 

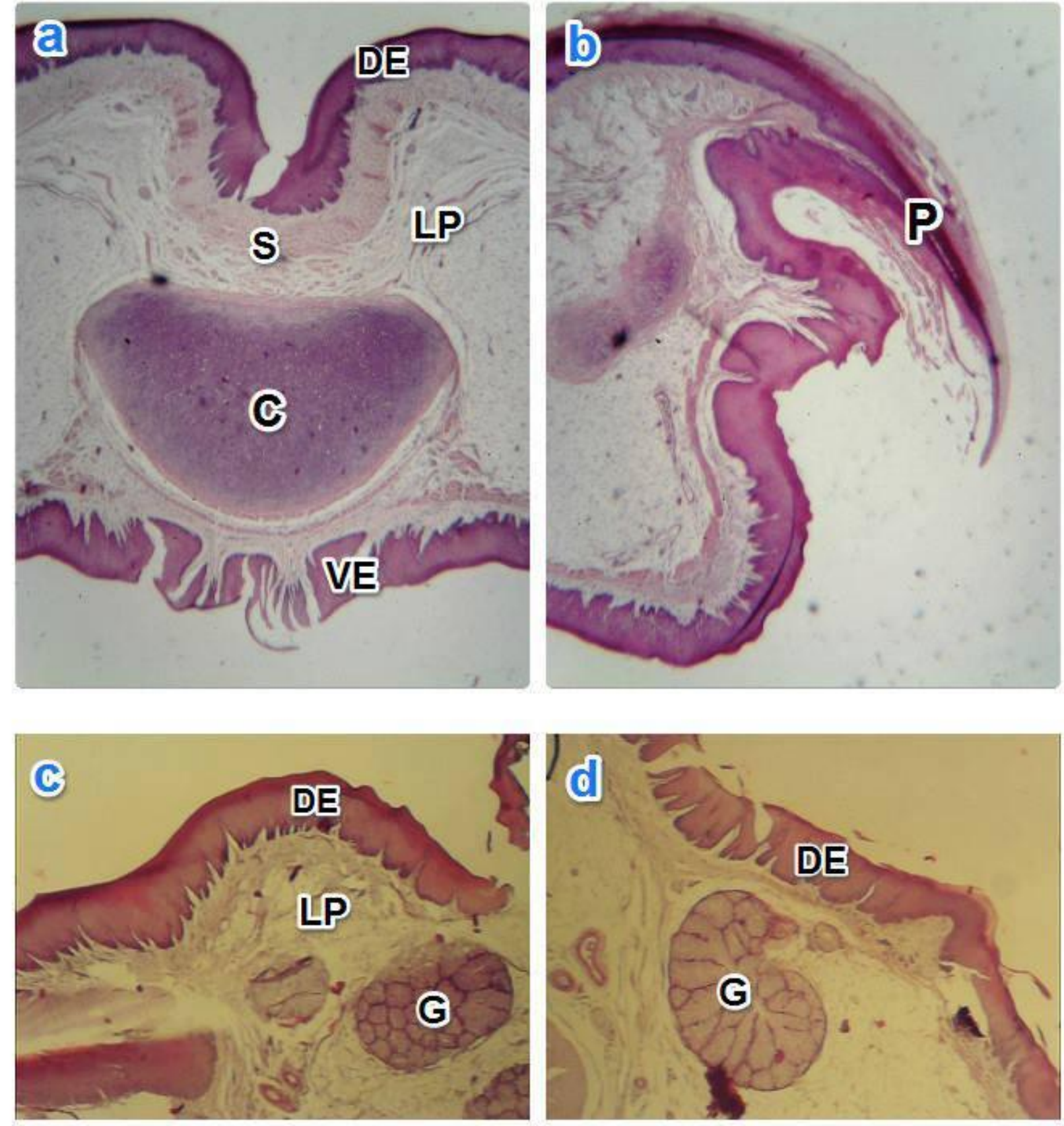

Fig. 5: Light photomicrograph of transverse sectionof the apex region of the tongue of Anascrecca (common teal),showing dorsal epithelium (DE), ventral epithelium (VE), hyoid cartilage (C) and skeletal muscles (S). Haematoxyline and eosin staining (40x) (a), apex region showing lingual papillae (P), lamina proparia (LP). Haematoxyline and eosin staining (40x) (b), Body region showing lamina proparia (LP) filled with large glandular units $(\mathrm{G})$ Haematoxyline and eosin staining (40x) (c), root region showing large glandular unit $(\mathrm{G})$ Haematoxyline and eosin staining (40x) (d). 


\section{References:-}

1. Al-Zahaby, S. A and Elsheikh, E. (2014):Ultramorphological and histological studies on the tongue of the common Kingfisher in relation to its feeding habit. The Jornal of Basic \& Applied Zoology, 67: 91-99.

2. Baussart, S.; Korsoun, L.; Libourel, P. A and Bels, V. (2009): Ballistic food transport in toucans. J. ExpZool A Ecol Genet Physiol, 311(7): 465-474.

3. El Bakary, N. E.R (2011): Surface morphology of the tongue of the hoopoe (Upupaepops). J Am Sci, 7: 394399.

4. El Bakary, N.E.R. (2012): Scanning electron microscope study of the dorsal lingual surface of Halcyon smyrnensis (White-breasted kingfisher). Global Vet, 9(2): 192-195.

5. El Bakary, N.E.R. (2015): Morphology of the Oropharyngeal Cavity of Northern Pintail (Anasacuta).Global Veterinaria, 14(4): 459-464.

6. El-Beltagy, A.M. (2013): Comparative studies on the tongue of white throated kingfisher (Halcyon smyrnensis) and common buzzard (Buteobuteo). Egypt. Acad. J. Biol. Sci, 4(1): 1-14.

7. Emura, S.; Okumura, T. and Chen, H. (2008): Scanning electron microscopic study of the tongue in the peregrine falcon and common kestrel Okajimas folia Anat. Jpn, 85(1): 11-15.

8. Emura, S.; Okumura, T. and Chen, H. (2009): Scanning electron microscopic study of the tongue in the Japanese pygmy woodpecker (Dendrocoposkizuki). Okajimas Folia Anat. Jpn, 86(1): 31-35.

9. Emura, S.; Okumura, T. and Chen, H. (2010): Comparative studies of the dorsal surface of the tongue in three avian species by Scanning Electron Microscopy. Okajimas Folia Anat. Jpn, 86(4): 111-115.

10. Emura, S.; Okumura, T. and Chen, H. (2011): Scanning electron microscopic study of the tongue in the rainbow lorikeet (Trichoglossushaematodus). Okajimas Folia Anat. Jpn, 88(1): 17-21.

11. Emura, S.; Okumura, T. and Chen, H. (2012): Scanning electron microscopic study on the tongue in the scarlet macaw (Aramacao). OkajimasFolia Anat. Jpn, 89(3): 57-60.

12. Erdoğan, S. and Iwasaki, S. I. (2014): Function-related morphological characteristics and specialized structures of the avian tongue. Annals of Anatomy-AnatomischerAnzeiger, 196(2): 75-87.

13. Getty, R. (1975):Sission and Grossman's: the anatomy of the domestic animals, $5^{\text {th }}$ ed. Philadelphia: W.B. saunders Company. Pp. 1857-1861,1891-1896.

14. Gonzalez, J.; Düttmann, H. and Wink, M. (2009): Phylogenetic relationships based on two mitochondrial genes and hybridization patterns in Anatidae. Journal of Zoology, 279: 310-318.

15. Hassan, S. M.; Moussa, E. A.and Cartwright, A. L. (2010): Variations by sex in anatomical and morphological features of the tongue of Egyptian goose (Alopochenaegyptiacus). Cells Tissues Organs, 191(2): 161-165.

16. Igwebuike, U.M. and Anagor, T.A. (2013): The morphology of the oropharynx and tongue of the Muscovy duck (Cairinamoschata).Vet. Arhiv, 83(6): 685-693.

17. Iwasaki, S. I. (1992): Fine structure of the dorsal lingual epithelium of the little tern, Sterna albifronsPalas (Aves, Lari). Morphol, 212:13-26.

18. Iwasaki, S. I. (2002): Evolution of the structure and function of the vertebrate tongue. Journal of Anatomy, 201(1): 1-13.

19. Iwasaki, S. I.; Asami, T. and Chiba, A. (1997): Anserfabalismiddendorffii (Anseres, Antidae). The Anatomical Record, 247: 149-163.

20. Jackowiak, H., and Godynicki, S. (2005): Light and scanning electron microscopic study of the tongue in the white tailed eagle (Haliaeetusalbicilla, Accipitridae, Aves). Annals of Anatomy-AnatomischerAnzeiger, 187(3): 251-259.

21. Jackowiak, H., and Ludwig, M. (2008): Light and scanning electron microscopic study of the structure of the ostrich (Strutiocamelus) tongue. Zoological Sci., 25(2): 188-194.

22. Jackowiak, H.; Andrzejewski, W. and Godynicki, S. (2006): Light and scanning electron microscopic study of the tongue in the cormorant Phalacrocoraxcarbo (Phalacrocoracidae, Aves). Japan. Zool. Sci. 23: 161-167.

23. Jackowiak, H.; Skieresz-Szewczyk, K.; Kwieciński, Z.; Trzcielińska-Lorych, J. and Godynicki, S. (2010): Functional morphology of the tongue in the nutcracker (Nucifragacaryocatactes). Zoological sci., 27(7): 589594.

24. Jackowiak, H., Skieresz-Szewczyk, K., Godynicki, S., Iwasaki, S. I., \& Meyer, W. (2011): Functional morphology of the tongue in the domestic goose (Anseranser f. domestica). The Anatomical Record, 294(9): 1574-1584.

25. Kear, J. (2005).Ducks, geese and swans. Volume 2. Species accounts (Cairina to Mergus).

26. Lagerquist, B. A. and Ankney, C. D. (1989): Interspecific differences in bill and tongue morphology among diving ducks (Aythya spp., Oxyurajamaicensis).Canadian journal of zoology, 67(11): 2694-2699. 
27. Nickel, R.; Schummer, A. \&Seiferle, E. (1977): Anatomy of the Domestic Birds, pp. 45-46. Verlag Paul Parey, Berlin-Hamburg.

28. Nudds, T. D., and Bowlby, J. N. (1984): Predator-prey size relationships in North American dabbling ducks. Canadian journal of zoology, 62(10): 2002-2008.

29. Parchami, A.; Dehkordi, R. F. andBahadoran, S. (2010): Fine structure of the dorsal lingual epithelium of the common quail (Coturnixcoturnix). World ApplSci J, 10(10): 1185-1189.

30. Pasand, A. P.;Tadjalli, M. andMansouri, H. (2010): Microscopic study on the tongue of male ostrich. European Journal of Biological Sciences, 2(2): 24-31.

31. Sağsöz, H.; Erdoğan, S. and Akbalik, M. E. (2013):Histomorphological structure of the palate and histochemical profiles of the salivary palatine glands in the Chukar partridge (Alectorischukar, Gray 1830). Acta Zool., 94: 382-391.

32. Skieresz-Szewczyk, K. andJackowiak, H. (2014): Scanning electron microscopy investigation of the filterfeeding apparatus in the domestic goose (Anseranser f. domestica) and the domestic duck (Anasplatyrhynchos f. domestica). Microscopy: advances in scientific research and education(A. Méndez-Vilas, Ed.), 1: 84-88.

33. Skieresz-Szewczyk, K., and Jackowiak, H. (2016): Morphofunctional study of the tongue in the domestic duck (Anasplatyrhynchos f. domestica, Anatidae): LM and SEM study. Zoomorphology, 135(2): 255-268.

34. Tabak, L. A.; Levine, M. J.; Mandel, I. D., and Ellison, S. A. (1982): Role of salivary mucins in the protection of the oral cavity. Journal of Oral Pathology \& Medicine, 11(1): 1-17. 